\title{
Concordance between medical records and interview data in correctional facilities
}

\author{
Jennifer R Bai ${ }^{1 *}$, Dhritiman V Mukherjee ${ }^{1,2,3}$, Montina Befus ${ }^{1,2}$, Zoltan Apa ${ }^{1}$, Franklin D Lowy ${ }^{3}$ and Elaine L Larson ${ }^{1,2}$
}

\begin{abstract}
Background: Self- administered questionnaires or interviews and medical records are often used as sources of research data; thus it is essential to evaluate their concordance and reliability. The aim of this paper was to assess the concordance between medical and behavioral data obtained from medical records and interview questionnaires in two correctional facilities.
\end{abstract}

Methods: Medical record and interview data were compared for 679 inmates from one male and one female maximum security prison between April 2010 and February 2013. Gender non-stratified and gender-stratified analyses were conducted in SPSS to calculate the prevalence and kappa coefficient scores (K) for medical (e.g., HIV, diabetes, hypertension) and behavioral (e.g., smoking, drug use, tattoos) conditions. Sensitivity/specificity between medical records and interview were calculated in the gender non-stratified data.

Results: In the gender non-stratified analysis, $\mathrm{k}$ score for HIV, hepatitis C, diabetes, asthma, and history of tattoos had strong or good concordance (0.66-0.89). Hypertension, renal/kidney disease, cigarette smoking, antibiotic use in the last 6 months, and cocaine use ever were moderately correlated (0.49-0.57). Both history of any illicit drug use ever (0.36) and marijuana use ever (0.23) had poor concordance. Females had higher $\mathrm{k}$ scores and prevalence rates than males overall. Medical conditions were reported more frequently in medical records and behavioral conditions had higher prevalence in interviews. Sensitivity for medical conditions in the combined facility data ranged from $50.0 \%$ to $86.0 \%$ and $48.2 \%$ to $85.3 \%$ for behavioral conditions whereas specificity ranged from $95.9 \%$ to $99.5 \%$ for medical conditions and $75.9 \%$ to $92.8 \%$ for behavioral conditions.

Conclusion: Levels of agreement between medical records and self-reports varied by type of factor. Medical conditions were more frequently reported by chart review and behavioral factors more frequently by self-report. Data source used may need to be chosen carefully depending upon the type of information sought.

Keywords: Medical records, Interviews, Questionnaires, Self-reports, Concordance, Reliability, Agreement, Kappa statistics

\section{Background}

Medical records, interviews and self-administered questionnaires are frequently used sources of research data, thus many studies have assessed the concordance and reliability between these data collection methods. Although some researchers have considered medical records as the "gold standard" and the preferred data source over questionnaires, evidence indicates that neither source is completely accurate and that combining sources may result in a more reliable and complete data assessment [1-5]. Any

\footnotetext{
* Correspondence: rb2750@cumc.columbia.edu

'School of Nursing, Columbia University, New York, NY, USA

Full list of author information is available at the end of the article
}

method of data collection can introduce its own sources of measurement error. Questionnaire data, either from self-report or interview, have limitations such as recall bias, misinterpretation of the questions and degree of willingness to report. On the other hand, medical record data may also be limited by illegibility; incomplete, inaccurate or missing documentation; and limited availability of data elements $[2,6-8]$. Furthermore, medical records are designed for clinical rather than research purposes. Thus, multiple challenges exist regarding what data to extract and how, especially when multiple investigators are involved if a standardized extraction protocol is not established $[9,10]$.

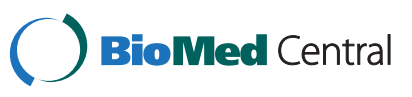

(c) 2014 Bai et al.; licensee BioMed Central Ltd. This is an Open Access article distributed under the terms of the Creative Commons Attribution License (http://creativecommons.org/licenses/by/2.0), which permits unrestricted use, distribution, and reproduction in any medium, provided the original work is properly credited. 
While published population-based studies have examined the concordance between medical records and questionnaire data for chronic medical conditions and its related symptoms [3,4,11-13], we did not find literature within the past decade that summarized and compared the reliability and concordance between these two data sources in an incarcerated population. Because we were collecting data for a research study and drawing inferences from these data which could have an impact on clinical care and policies (see 'Study population' below), it was essential to determine the extent to which various data sources were complete, available, and consistent. Therefore, the aim of this study was to assess the concordance between medical records and interview questionnaires for medical and behavioral conditions obtained from two maximum security correctional facilities.

\section{Methods}

\section{Study population}

We used medical record and interview data collected from an ongoing study, "Risk Factors for Spread of Staphylococcus aureus in Prisons" (NIH, ROI AI82536), which was approved by the institutional review boards of New York State Department of Corrections and Community Supervision (DOCCS) and Columbia University Medical Center. This study is being conducted in two maximum security prisons: Bedford Hills Correctional Facility for Women which houses about 900 inmates at Bedford Hills, NY and Sing Sing Correctional Facility for Men with about 1800 inmates at Ossining, NY [14]. The method of recruitment of inmates was tailored to the processing regulations and safety policies of the two prisons and has been previously described [15]. Eligibility for participation included: (1) at least 16 years of age, (2) introduced into the general incarcerated population for at least six months, and (3) ability to speak and read English.

\section{Collection of data sources}

After obtaining signed informed consent, a trained research assistant interviewed the inmate in a private room using a structured questionnaire which included questions regarding demographics, education level, daily activities and general hygiene. Participants were asked more specifically regarding personal medical history (e.g., "Do you have any pulmonary disease such as asthma?"), previous skin infections, antibiotic use in the last six months, current tobacco/cigarette smoking and history of drug use. Correctional officers escorted them to the room but were not present during the interview process. Medical records data were collected independently following the interviews for those who agreed to participate in the study.

\section{Data extraction}

Medical record data were extracted from paper-based medical charts by two fulltime, training research assistants. All records were filed in order of the inmate's identification number in the medical record office and were easily accessible by the research assistants. All inmate medical records consisted of a medical history problem list, handwritten notes from health care providers, psychiatric information, laboratory results, drug prescription charts, and physical examination reports that included drug use history and sexual orientation. For the concordance analysis, we extracted variables that were previously examined in the literature as well as other variables of interest that were available from both the medical records and interview questionnaires. Information regarding antibiotic use in the six months prior to the interview date regardless of their site of residency was found mainly in the handwritten notes and sometimes in the drug prescription charts, if present in the inmate's file. From the list of medical history and the most recent physical examination reports, we were able to identify the following: chronic medical conditions such as asthma, diabetes, renal/kidney disease, hypertension (including those who reported high blood pressure), hepatitis $\mathrm{C}$, and $\mathrm{HIV}$, and behavioral conditions including current cigarette smoking, and history of tattoos, marijuana use, cocaine use, and any illicit drug use.

\section{Statistical analyses}

Medical records and interview questionnaire data were analyzed in IBM SPSS Statistics Version 20 (SPSS, Inc., Chicago IL, USA). The prevalence of each variable was calculated from each source. The kappa (к) coefficient was computed to assess the concordance between the medical record and interview for each variable of interest. The kappa value ( 0.00 to 1.00$)$ was categorized as suggested by Landis and Koch, 1977 [16] as: poor $(<0.20)$; fair (0.21-0.40); moderate (0.41-0.60); good (0.61-0.80) and strong (0.81-1.00). Two separate analyses were conducted, gender non-stratified and gender stratified, to compare any differences in the kappa score and prevalence by gender. Because the results between the two analyses were similar, sensitivity and specificity were only calculated using the gender non-stratified data. Similar to Tisnado et al. [5], we also considered the data source with the highest prevalence (either medical records or interviews) as the 'gold standard' when calculating sensitivity and specificity.

\section{Results}

\section{Population characteristics}

In the two correctional facilities, 801 inmates participated in the parent study between April 2010 to February 2013 (participation rate $=82.7 \%$ ). A total of 679 participants for 
whom that had all the variables of interest presented in both interview and medical record data were included in this analysis. As summarized in Table 1, more than half of participants were black non-Hispanic (53.5\%), followed by white non-Hispanic (22.5\%) and Hispanic (21.4\%). There were more female $(55.5 \%)$ than male $(44.5 \%)$ participants, and ages $<25$ years old (15.9\%), 26-35 years old (30.9\%), $36-50(43.2 \%)$, > 51 years old (10\%), mean: 37 years.

\section{Prevalence of medical condition variables}

In the gender combined analysis, prevalence rates of all variables in the medical condition category were higher in the medical records when compared with the interview questionnaires. Asthma (39.6\%) was the most prevalent condition and renal/kidney disease $(2.5 \%)$ was the least prevalent condition among the inmates. Females had a higher prevalence of both medical and behavioral conditions in both data sources when compared to males, with asthma still as the most prevalent condition (females$47.2 \%$ vs. males- $30.1 \%$ ) and renal/kidney disease as the least prevalent condition (females- $3.2 \%$ vs. males- $1.7 \%$ ). For females only, all medical conditions were reported more frequently in medical records when compared with the interviews, except for diabetes $(9.1 \%$ vs. $9.3 \%)$ and renal/kidney disease (3.2\% vs. 3.7\%) (Table 2 ).

\section{Prevalence of behavioral condition variables}

For the gender combined data, all behavioral condition variables were more likely to be reported in the interview questionnaires than in the medical records including any illicit drug use ever ( $83.8 \%$ vs. $66.1 \%$, respectively), marijuana use ever ( $76.6 \%$ vs. $39.9 \%$, respectively), and antibiotic use in the last six months (31.5\% and $34.6 \%$, respectively). After stratifying by gender, behavioral conditions were still

Table 1 Demographics, gender and age of inmate participants

\begin{tabular}{ll}
\hline Characteristics & Study population $\mathbf{N}=\mathbf{6 7 9}(\%)$ \\
\hline Sex & \\
$\quad$ Male & $302(44.5 \%)$ \\
$\quad$ Female & $377(55.5 \%)$ \\
Age, years (mean age = 37) & \\
$<25$ & $108(15.9 \%)$ \\
$26-35$ & $210(30.9 \%)$ \\
$36-50$ & $293(43.2 \%)$ \\
$>51$ & $68(10.0 \%)$ \\
Race/Ethnicity & \\
White non-Hispanic & $153(22.5 \%)$ \\
Black non-Hispanic & $363(53.5 \%)$ \\
Hispanic & $145(21.4 \%)$ \\
Others & $18(2.65 \%)$ \\
\hline
\end{tabular}

more likely to be reported in the questionnaires except for history of tattoos in the female, which had the same reported prevalence rates in both questionnaire and medical record (Table 2).

\section{Concordance between medical records and interview questionnaires}

The kappa coefficients for the combined facilities and gender stratified analyses ranged from 0.19 to 0.91 , with all scores statistically significant ( $\mathrm{P}$-value $<0.01)$. In the gender combined data, HIV $(\kappa=0.89)$ and diabetes $(\kappa=0.82)$ had the highest kappa scores between medical records and questionnaires, followed by asthma $(\kappa=0.78)$, hepatitis $C(\kappa=0.66)$, and history of tattoos $(\kappa=0.76)$ whereas marijuana use ever $(\kappa=0.23)$ and any illicit drug use ever $(\kappa=0.36)$ had the lowest kappa scores. In general, variables in the medical condition category had better kappa statistics (range $\mathrm{K}=0.50-0.89$ ) compared to variables in behavioral condition category (range $\mathrm{K}=0.23-0.76$ ).

Overall, females had higher kappa scores than males in both medical and behavioral condition categories. The only kappa score lower among females than males was cigarette smoking, although the differences were small ( $\kappa=0.51$ vs. 0.55 , respectively). Marijuana use ever $(\kappa=0.19)$ and any illicit drug use ever $(\kappa=0.26)$ had the lowest kappa scores in males, whereas the female population scored almost twice as high in both variables (Table 3).

\section{Sensitivity and specificity}

Using medical records as the gold standard in the medical condition category, sensitivity ranged from $50.0 \%$ to $86.0 \%$ and specificity from $95.9 \%$ to $99.5 \%$. Sensitivity was $<60 \%$ for hepatitis C, hypertension, and renal/kidney disease. HIV (86.0\%) and diabetes (81.6\%) had the highest sensitivities. Specificity was high for all the variables, ranging from $95.9 \%$ to $99.5 \%$.

The questionnaire was used as gold standard for the behavioral condition category. Sensitivities for behavioral conditions ranged from $48.2 \%$ to $85.3 \%$ and for specificity, $75.9 \%$ to $92.8 \%$ Tattoos had the highest sensitivity $(85.3 \%)$ and marijuana use ever was the lowest (48.2\%). Specificity was lower and less consistent than that of the medical condition category, ranging from $75.9 \%$ for cigarette smoking to $92.8 \%$ for tattoos (Table 3).

\section{Discussion}

We evaluated the concordance between medical records and interview questionnaires for medical and behavioral conditions in two incarcerated populations in New York State. Similar to the findings of Schofield et al. [17], we found that inmates were generally reliable respondents for health-focused surveys. Overall, our findings were consistent with previously published studies conducted 
Table 2 Prevalence of medical and behavioral conditions are reported in medical records and interviews by male and female participants

\begin{tabular}{|c|c|c|c|c|c|c|}
\hline \multirow[t]{3}{*}{ Medical Conditions } & \multicolumn{2}{|c|}{ Males } & \multicolumn{2}{|c|}{ Females } & \multicolumn{2}{|c|}{ Overall Prevalence } \\
\hline & \multicolumn{2}{|c|}{$\%(\mathrm{~N}=302)$} & \multicolumn{2}{|c|}{$\%(\mathrm{~N}=377)$} & \multicolumn{2}{|c|}{$\%(\mathrm{~N}=679)$} \\
\hline & Medical record & Interview & Medical record & Interview & Medical record & Interview \\
\hline Asthma & 30.1 & 21.5 & 47.2 & 39.3 & 39.6 & 31.4 \\
\hline Hypertension & 16.6 & 10.3 & 22.5 & 17.2 & 19.9 & 14.1 \\
\hline Hepatitis C & 10.6 & 5.3 & 18.3 & 12.2 & 14.9 & 9.1 \\
\hline Diabetes* & 4.9 & 3.9 & 9.1 & 9.3 & 7.2 & 6.9 \\
\hline HIV & 2.3 & 1.9 & 9.5 & 9.0 & 6.3 & 5.9 \\
\hline Renal/kidney disease & 1.7 & 1.3 & 3.2 & 3.7 & 2.5 & 2.7 \\
\hline \multirow[t]{3}{*}{ Behavioral conditions } & \multicolumn{2}{|c|}{ Males } & \multicolumn{2}{|c|}{ Females } & \multicolumn{2}{|c|}{ Overall Prevalence } \\
\hline & \multicolumn{2}{|c|}{$\%(N=302)$} & \multicolumn{2}{|c|}{$\%(N=377)$} & \multicolumn{2}{|c|}{$\%(\mathrm{~N}=679)$} \\
\hline & Medical record & Interview & Medical record & Interview & Medical record & Interview \\
\hline Cigarette smoking* & 60.4 & 64.4 & 74.0 & 82.0 & 67.9 & 74.2 \\
\hline All illicit drugs use ever* & 50.8 & 81.9 & 78.0 & 85.4 & 66.1 & 83.8 \\
\hline Tattoos & 48.7 & 61.6 & 57.0 & 57.0 & 53.3 & 59.1 \\
\hline Marijuana use ever* & 37.8 & 78.6 & 41.3 & 75.2 & 39.9 & 76.6 \\
\hline Cocaine use ever* & 19.4 & 24.1 & 48.4 & 55.0 & 35.7 & 41.3 \\
\hline Antibiotic usage in last 6 months* & 17.9 & 23.9 & 42.0 & 43.1 & 31.5 & 34.6 \\
\hline
\end{tabular}

*Denominator excludes missing data.

in either a community or clinical settings; the prevalence of chronic medical conditions except for renal/kidney disease was higher in the medical records when compared to the questionnaires, which could be due to under-reporting in the interviews, as has been previously reported [13,17-20]. Similarly, behavioral conditions are likely to have been under-reported in the medical records, especially for variables such as drugs and antibiotics. In contrast to a literature summary by Garber et al. [21], we found that interviews had just as good concordance as self-administered questionnaires when compared with medical records.

Like Okura, et al. [3], which was published almost a decade ago, and Malik et al. [19], a more recent study,

Table 3 Comparison of agreement between medial records and inmate interviews: Kappa coefficients, sensitivity and specificity

\begin{tabular}{|c|c|c|c|c|c|}
\hline \multirow[t]{2}{*}{ Medical condition } & \multicolumn{3}{|c|}{ K coefficient ${ }^{* *}$} & \multicolumn{2}{|c|}{ Medical record as gold standard (Overall) } \\
\hline & Male & Female & Overall & Sensitivity (\%) & Specificity (\%) \\
\hline HIV & 0.76 & 0.91 & 0.89 & 86.0 & 99.5 \\
\hline Diabetes* & 0.81 & 0.82 & 0.82 & 81.6 & 98.9 \\
\hline Asthma & 0.73 & 0.81 & 0.78 & 76.9 & 98.5 \\
\hline Hepatitis C & 0.55 & 0.71 & 0.66 & 56.4 & 99.1 \\
\hline Hypertension & 0.51 & 0.60 & 0.57 & 54.8 & 95.9 \\
\hline Renal/kidney disease & 0.44 & 0.52 & 0.50 & 50.0 & 98.8 \\
\hline \multirow[t]{2}{*}{ Behavioral conditions } & \multicolumn{3}{|c|}{ K coefficient ${ }^{* *}$} & \multicolumn{2}{|c|}{ Interview questionnaires as gold standard (Overall) } \\
\hline & Male & Female & Overall & Sensitivity (\%) & Specificity (\%) \\
\hline Tattoos & 0.65 & 0.87 & 0.76 & 85.3 & 92.8 \\
\hline Cigarette smoking* & 0.55 & 0.51 & 0.55 & 83.0 & 75.9 \\
\hline Antibiotic usage in last 6 months* & 0.45 & 0.51 & 0.51 & 64.1 & 86.0 \\
\hline Cocaine use ever* & 0.43 & 0.43 & 0.49 & 63.7 & 84.1 \\
\hline All illicit drugs use ever * & 0.21 & 0.54 & 0.36 & 74.6 & 77.9 \\
\hline Marijuana use ever* & 0.19 & 0.26 & 0.23 & 48.2 & 87.3 \\
\hline
\end{tabular}

*Denominator excludes missing data.

**P-values for all variable are significant $(P<0.01)$. 
we also found strong concordance between medical records and questionnaire responses for HIV and diabetes, which could indicate that most participants were aware of their diagnoses and willing to disclose that information $[3,12,13,19,20]$.

Consistent with findings of Iversen, et al., Leikauf et al., and Tisnado, et al., we also found good concordance for reporting of asthma $[5,13,18]$. Hepatitis $\mathrm{C}$, on the other hand, had a lower concordance level and was more likely to be reported by medical record, suggesting that participants were either unaware of their status or unwilling to report to the investigators.

In contrast to medical conditions, all behavioral conditions were reported more frequently in the interview questionnaires than in the medical records. Reports on history of any illicit drug use and marijuana use had the lowest kappa scores and the greatest difference between the two sources, perhaps because inmates are less likely to report drug use to health care providers during the physical examination than to the interviewers in fear of reprehension. Our kappa scores for current cigarette smoking and cocaine use were slightly lower than those reported in a previous study [19]. Since certain medical information was not up to date, the most recent reports of current cigarette smoking might not be representative of the inmate's current smoking habits. A history of tattoos, on the other hand, had the best concordance and highest sensitivity/specificity in behavioral conditions. This could be explained by the fact that tattoos are noticeable and legal, thus inmates may not be wary of reporting them. Overall, interview questionnaires may be a better source of data for behavioral conditions than the medical record.

After gender stratification, no significant differences were found as compared to the gender non-stratified analysis; however, females did report much higher prevalence and concordance levels than males for all variables, also consistent with previous research $[20,22]$. Since both facilities have similar medical care accessible to inmates, this difference could be due to actual higher prevalence of conditions in females, the fact that females may be more aware and health conscience than males, therefore more willing to share information, or that females tend to frequent medical unit more often than males. Further studies on gender differences should be conducted to clarify these distinctions.

This study had limitations and bias that could have affected our findings. The incarcerated population may not be generalizable to other populations. As previously reported, medical records are often incomplete, missing information, or not up to date $[2,7,17,18]$. Specifically in this study, the medical records were handwritten, not electronic records like in the population-based studies, thus it was difficult to retrieve the necessary or, at time, accurate information. We did not record the length of time required to extract data from the medical records, but it varied considerably, depending upon the handwriting in the notes. Clearly, data extraction would be greatly facilitated in electronic medical records.

Because two research assistants were conducting the interviews and extracting from the medical charts, there could be variations in data collection processes and interpretation. However, this did not have any significant effect on the data analysis or results, since the medical record form was straightforward and both research assistants were trained to follow a standardized extraction protocol. Furthermore, studies have shown high kappa scores and percent agreement of intra- rater and interrater reliability for medical record extraction [10,23,24]. Most importantly, for many of the variables we examined, particularly the behavioral factors such as sexual practices, it was not possible to assess validity because there was no confirmatory 'gold standard'. Nevertheless, our findings should provide some guidance as to when the medical record or self-report might be the most reliable data source.

\section{Conclusion}

Medical records and self-reports are often data sources used in research, thus it is essential for investigators to analyze the concordance between the two for any variables of interest. While our findings were similar to what has been previously reported for chronic medical conditions regardless of the dissimilarity in study population, the level of concordance between the two sources varied greatly depending on the variable. Hence, investigators should choose data sources and construct questionnaire forms carefully depending on the population and variables of interest.

\section{Abbreviations}

DOCCS: New York State Department of Corrections and Community Supervision; NIH: US National Institutes of Health.

\section{Competing interests}

The authors declare that they have no competing interests.

\section{Authors' contributions}

RB was involved in conceptualization, literature search, writing and data interpretation of the study. DVM and MB contributed to editing the manuscript and data analysis. ZA helped with data collection. All authors read and approved the final manuscript.

\section{Acknowledgements}

In addition to the authors, we would like to acknowledge data collector Carolyn T.A. Herzig, MS, Department of Epidemiology, Mailman School of Public Health, Columbia University, New York, NY, USA

We thank DOCS personnel who made this research possible including Carl Koenigsmann, MD, New York State Department of Corrections, Albany, NY, USA; Sabina Kaplan, Superintendent at Bedford Hills Correctional Facility, Bedford Hills, NY, USA; Michael Capra, Superintendent at Sing Sing Correctional Facility, Ossining, NY, USA; Dr. Dana Gage, Medical Director at Sing Sing Correctional Facility, Ossining, NY, USA. 
This research was supported by grants from the US National Institutes of Health to F.D.L and E.L.L (RO1 Al82536).

\section{Author details}

${ }^{1}$ School of Nursing, Columbia University, New York, NY, USA. ${ }^{2}$ Department of Epidemiology, Mailman School of Public Health, Columbia University, New York, NY, USA. ${ }^{3}$ Department of Medicine, Division of Infectious Diseases, College of Physicians and Surgeons, Columbia University, New York, NY, USA.

Received: 27 August 2013 Accepted: 17 March 2014

Published: 9 April 2014

\section{References}

1. Goulet F, Jacques A, Gagnon R, Racette P, Sieber W: Assessment of family physicians' performance using patient charts: interrater reliability and concordance with chart-stimulated recall interview. Eval Health Prof 2007, 30(4):376-392

2. Corser W, Sikorskii A, Olomu A, Stommel M, Proden C, Holmes-Rovner M Concordance between comorbidity data from patient self-report interviews and medical record documentation. BMC Health Serv Res 2008, 8:85.

3. Okura Y, Urban LH, Mahoney DW, Jacobsen SJ, Rodeheffer RJ: Agreement between self-report questionnaires and medical record data was substantial for diabetes, hypertension, myocardial infarction and stroke but not for heart failure. J Clin Epidemiol 2004, 57(10):1096-1103.

4. St Sauver JL, Hagen PT, Cha SS, Bagniewski SM, Mandrekar JN, Curoe AM, Rodeheffer RJ, Roger VL, Jacobsen SJ: Agreement between patient reports of cardiovascular disease and patient medical records. Mayo Clin Proc 2005, 80(2):203-210.

5. Tisnado DM, Adams JL, Liu H, Damberg CL, Chen WP, Hu FA, Carlisle DM, Mangione CM, Kahn KL: What is the concordance between the medical record and patient self-report as data sources for ambulatory care? Med Care 2006, 44(2):132-140.

6. Barbara AM, Loeb M, Dolovich L, Brazil K, Russell ML: Patient self-report and medical records: measuring agreement for binary data. Can Fam Physician 2011, 57(6):737-738

7. Skinner KM, Miller DR, Lincoln E, Lee A, Kazis LE: Concordance between respondent self-reports and medical records for chronic conditions: experience from the Veterans Health Study. J Ambulatory Care Manage 2005, 28(2):102-110.

8. Fathelrahman Al: Agreement between questionnaire and medical records on some health and socioeconomic problems among poisoning cases. BMC Res Notes 2009, 2:183.

9. Alves E, Lunet N, Correia S, Morais V, Azevedo A, Barros H: Medical record review to recover missing data in a Portuguese birth cohort: agreement with self-reported data collected by questionnaire and inter-rater variability. Gac Sanit 2011, 25(3):211-219.

10. Liddy C, Wiens M, Hogg W: Methods to achieve high interrater reliability in data collection from primary care medical records. Ann Fam Med 2011, 9(1):57-62.

11. Barbara AM, Loeb M, Dolovich L, Brazil K, Russell M: Agreement between self-report and medical records on signs and symptoms of respiratory illness. Prim Care Respir J 2012, 21(2):145-152.

12. Eze-Nliam C, Cain K, Bond K, Forlenza K, Jankowski R, Magyar-Russell G, Yenokyan G, Ziegelstein RC: Discrepancies between the medical record and the reports of patients with acute coronary syndrome regarding important aspects of the medical history. BMC Health Serv Res 2012, 12:78.

13. Leikauf J, Federman AD: Comparisons of self-reported and chart-identified chronic diseases in inner-city seniors. J Am Geriatr Soc 2009, 57(7):1219-1225.

14. Lee CJ, Sankaran S, Mukherjee DV, Apa ZL, Hafer CA, Wright L, Larson EL, Lowy FD: Staphylococcus aureus oropharyngeal carriage in a prison population. Clin Infect Dis 2011, 52(6):775-778.

15. Apa ZL, Bai R, Mukherejee DV, Herzig CT, Koenigsmann C, Lowy FD, Larson EL: Challenges and strategies for research in prisons. Public Health Nurs 2012, 29(5):467-472.

16. Landis JR, Koch GG: The measurement of observer agreement for categorical data. Biometrics 1977, 33(1):159-174.

17. Schofield P, Butler T, Hollis S, D'Este C: Are prisoners reliable survey respondents? A validation of self-reported traumatic brain injury (TBI) against hospital medical records. Brain Inj 2011, 25(1):74-82.
18. Iversen L, Hannaford PC, Godden DJ, Price D: Do people self-reporting information about chronic respiratory disease have corroborative evidence in their general practice medical records? A study of intermethod reliability. Prim 2007, 16(3):162-168.

19. Malik AS, Giamouzis G, Georgiopoulou W, Fike LV, Kalogeropoulos AP, Norton CR, Sorescu D, Azim S, Laskar SR, Smith AL, Dunbar SB, Butler : Patient perception versus medical record entry of health-related conditions among patients with heart failure. Am J Cardiol 2011, 107(4):569-572.

20. Merkin SS, Cavanaugh K, Longenecker JC, Fink NE, Levey AS, Powe NR Agreement of self-reported comorbid conditions with medical and physician reports varied by disease among end-stage renal disease patients. J Clin Epidemiol 2007, 60(6):634-642.

21. Garber MC, Nau DP, Erickson SR, Aikens JE, Lawrence JB: The concordance of self-report with other measures of medication adherence: a summary of the literature. Med Care 2004, 42(7):649-652.

22. LaVene MC, White MC, Waters CM, Tulsky JP: Screening for health conditions in a County Jail: differences by gender. $J$ Correct Health Care 2003, 9(4):381-396.

23. To T, Estrabillo E, Wang C, Cicutto L: Examining intra-rater and inter-rater response agreement: a medical chart abstraction study of a communitybased asthma care program. BMC Med Res Methodol 2008, 8:29.

24. Mi MY, Collins JE, Lerner V, Losina E, Katz JN: Reliability of medical record abstraction by non-physicians for orthopedic research. BMC Musculoskelet Disord 2013, 14:181.

doi:10.1186/1471-2288-14-50

Cite this article as: Bai et al:: Concordance between medical records and interview data in correctional facilities. BMC Medical Research Methodology 2014 14:50.

\section{Submit your next manuscript to BioMed Central and take full advantage of:}

- Convenient online submission

- Thorough peer review

- No space constraints or color figure charges

- Immediate publication on acceptance

- Inclusion in PubMed, CAS, Scopus and Google Scholar

- Research which is freely available for redistribution 